Revista Destaques Acadêmicos, Lajeado, v. 11, n. 3, 2019. ISSN 2176-3070

DOI: http://dx.doi.org/10.22410/issn.2176-3070.v11i3a2019.2087

http://www.univates.br/revistas

\title{
DAR VOZ A QUEM NÃO É OUVIDO: PERCEPÇÃO DE PESSOAS COM DEFICIÊNCIA FÍSICA SOBRE O SEU PODER DE CONSUMO
}

\author{
Jeinifer Soares Silveira ${ }^{1}$, Lydia Koetz Jaeger ${ }^{2}$
}

Resumo: A fim de conhecer a percepção das Pessoas com Deficiência sobre o seu poder de consumo em estabelecimentos comerciais e locais de lazer, o artigo teve como objetivo problematizar a inserção da pessoa com deficiência no convívio social, como sujeito autônomo em relação ao consumo em diversos setores. Realizou-se um estudo descritivo, exploratório e qualitativo, em uma Instituição de Ensino Superior de uma cidade do Vale do Taquari, no Rio Grande do Sul, tendo a amostra constituída por Pessoas com Deficiência, que exerçam papel de consumidores. Os resultados foram obtidos por meio de análise de conteúdo, apontando que conhecer o que as Pessoas com Deficiência pensam e o que elas têm a sugerir é de extrema importância para o contínuo aperfeiçoamento e construção de um ambiente inclusivo.

Palavras-chave: Pessoa com deficiência. Inclusão. Autonomia. Estabelecimentos Comerciais. Ambientes de Lazer.

\section{INTRODUÇÃO}

De acordo com a Lei $\mathrm{n}^{\circ} 13.146$, de julho de 2015, o conceito de PcD a caracteriza como sujeito que possui restrição de natureza física, mental ou sensorial que quando em sociedade, tenha algum empecilho quanto a participação efetiva com igualdade de condições aos demais. Essa lei, também denominada Estatuto da Pessoa com Deficiência, garante direitos fundamentais, tais como acessibilidade, possibilitando condições de alcance, para utilização de mobiliários, equipamentos urbanos, edificações, transportes e tecnologia, com segurança e igualdade aos demais, e qualquer tipo de barreira que impeça a participação social da pessoa, incluindo barreiras urbanísticas, atitudinais, arquitetônicas, nos transportes e comunicação (BRASIL, 2015).

1 Fisioterapeuta graduada pela Universidade do Vale do Taquari - Univates.

2 Mestre e Doutora em Ambiente e Desenvolvimento pela Universidade do Vale do Taquari Univates. 
O Censo Demográfico do ano de 2010, apontou que no Brasil pouco mais de 45 milhões de pessoas declaram possuir algum tipo de deficiência em diferentes níveis de acometimento, correspondendo a aproximadamente $24 \%$ da população brasileira (IBGE, 2010). Estas pessoas são potenciais consumidoras de bens e serviços, e nesse contexto, problematizar a autonomia das PcD em relação ao seu poder de consumo é de extrema importância.

Desde os primórdios, pessoas com diferenças que se sobressaem em relação à maioria são alvos de vários tipos de violências e preconceitos (MAZZOTTA; D'ANTINO, 2011). Interagir com essas pessoas tende a gerar desconforto para os demais, e para que este seja um obstáculo superado é necessário estimular o convívio social e respeito às diferenças (CONSOLO; GIANULLO, 2011).

Além de obstáculos atitudinais, que se referem aos inúmeros tipos de preconceitos enfrentados pela $\mathrm{PcD}$, o espaço físico é um outro grande obstáculo encontrado, pois o mesmo deve ser idealizado sob um panorama de diversidade, sendo que, somente assim haverá possibilidade de suprimir as barreiras que impossibilitam o acesso de todas as pessoas aos mais diversos ambientes (LIMA; CARVALHO-FREITAS; SANTOS, 2013). A esse respeito, percebe-se que o preconceito, a falta de preparo de profissionais, estrutura física, entre outras limitações, são fatores impeditivos para que a inclusão aconteça com efetividade nos estabelecimentos comerciais e ambientes de lazer.

Diante desse contexto, conhecer a percepção das PcD é de extrema importância para a ruptura destas barreiras e facilitação de mais um passo no processo de inclusão.

O presente estudo abordou a problematização da inserção da pessoa com deficiência no convívio social, como sujeito autônomo em relação ao consumo em diversos setores. $\mathrm{O}$ objetivo do estudo foi analisar as potencialidades e as dificuldades das $\mathrm{PcD}$, em relação à autonomia, acessibilidade e direito de compra.

\section{METODOLOGIA}

Tratou-se de um estudo descritivo, exploratório e qualitativo, desenvolvido em uma Instituição de Ensino Superior de uma cidade do Vale do Taquari, no Rio Grande do Sul, com 78.486 habitantes, e destes, mais de 17 mil possuem algum tipo de deficiência (IBGE, 2010). A amostra foi constituída por PcD que exerçam papel de consumidores e participavam de atendimentos fisioterapêuticos oferecidos na Clínica Escola de Fisioterapia ou trabalhavam na Instituição de Ensino Superior. Os critérios de inclusão estabelecidos foram: PcD física aparente, incluindo alterações motoras em geral, visto que, quando a alteração é aparente, maiores são os obstáculos encontrados, principalmente os atitudinais; maiores de dezoito anos, que possuíam fala e cognição preservadas, que são consumidores, e que assinaram o Termo de Consentimento Livre e 
Esclarecido - TCLE. Foram excluídas PcD física com diagnóstico clínico que envolvia deficiência mental associada, problemas cognitivos e dificuldades na fala e audição. A amostra foi constituída de 5 pessoas com deficiência física aparente. Essas pessoas foram contatadas individualmente por e-mail e ligações telefônicas para agendamento da apresentação do estudo. Na data agendada, a pesquisadora apresentou o estudo ao trabalhador, leu, explicou o TCLE e aplicou a entrevista.

Foi realizada uma entrevista composta por 8 questões abertas e 1 questão objetiva, com finalidade de identificar as facilidades, dificuldades e fatores impeditivos encontrados pelas $\mathrm{PcD}$ no que se refere à autonomia quanto ao consumo, acesso, atendimento, possibilidades e disponibilidade de produtos nos estabelecimentos comerciais e de lazer.

A coleta dos dados ocorreu no período de março a maio de 2018. Para análise dos dados utilizou-se a análise de conteúdo conforme Lawrence Bardin: um tipo de análise que reúne várias técnicas com objetivo de analisar a comunicação como um todo, incluindo linguística (escrita e oral), códigos complexos, imagens e códigos semióticos. As entrevistas foram dirigidas por um entrevistador e gravadas por meio de diálogo aberto para verificação das categorias emergentes nas falas.

A análise de conteúdo proposta por Bardin foi subdividida em três etapas: (a) pré-análise; (b) exploração do material; (c) tratamento dos resultados obtidos e interpretação. A pré-análise fundamentou-se na sistematização, momento de transcrição das entrevistas que foram sujeitas à análise e objetivos que deram seguimento às interpretações das entrevistas. Na fase de exploração do material, foi realizada a codificação dos conteúdos das entrevistas e na última etapa, foi constituída pela organização de tabelas que possibilitaram a análise das entrevistas, as quais favoreceram a compreensão dos resultados. Das falas, emergiram quatro categorias para análise, quais sejam: categoria 1facilidades encontradas pelas $\mathrm{PcD}$ em relação aos estabelecimentos comerciais e locais de lazer; categoria 2- dificuldades encontradas pelas PcD em relação aos estabelecimentos comerciais e locais de lazer; categoria 3- autonomia em relação ao acesso e consumo nos estabelecimentos comerciais e locais de lazer e suas possibilidades; categoria 4- percepções quanto ao atendimento prestado em estabelecimentos comerciais e locais de lazer (BARDIN, 2012).

Quanto às considerações éticas, a pesquisadora providenciou, juntamente ao local onde ocorreu a pesquisa, a Carta de Anuência, conforme especifica a Resolução no 466/2012 - CNS/CONEP. Os dados da pesquisa, a identificação dos voluntários e do local foram mantidos em sigilo.

O presente estudo foi aprovado pelo Comitê de Ética em Pesquisa da Univates (Coep/Univates), sob o número de CAAE: 80977814.0000.5310, conforme regulamentado pela Resolução CNS 466/2012. 


\section{RESULTADOS}

Participaram do estudo 5 entrevistados, sendo três mulheres e dois homens, com idades entre 18 anos e 69 anos. Os entrevistados participantes deste estudo possuíam as seguintes deficiências: nanismo, hemiparesia proveniente de acidente vascular encefálico, lesão total de plexo braquial e trauma raquimedular.

No decorrer das entrevistas, identificou-se que os relatos predominantes nas falas ainda referem-se principalmente às dificuldades encontradas pelas $\mathrm{PcD}$ ao frequentarem estabelecimentos comerciais e locais de lazer. Dificuldades estas que podem ser exemplificadas pela indisponibilidade de produtos que atendam diferentes públicos, tais como: altura de mobiliários, acessibilidade urbana e o desrespeito, fatores estes que prejudicam a autonomia dos indivíduos.

Ao analisar as categorias emergentes nas falas, percebe-se o quanto a individualidade dos entrevistados faz diferença quando questionados sobre suas percepções em relação ao seu poder de consumo. Nesse sentido, identifica-se que a percepção do entrevistado é diretamente influenciada pelo tipo de deficiência que ele apresenta. Diante disso, as diferenças entre aparência física dos entrevistados e a atenção dispensada emerge claramente nas falas, como pode observar-se na reflexão dos entrevistados 01 e 03, em relação ao atendimento recebido em estabelecimentos comerciais:

Eu acredito que eu sou bem atendido sempre [...], às vezes a pessoa nem nota que tem uma dificuldade,[...] geralmente tu tens que falar pra ela, a tua dificuldade. Aí ela percebe que tu tem, mas ela sempre te ajuda, às vezes tem gente que nota, e quer te ajudar [....] eu acho que é melhor deixar pra pessoa pedir ajuda às vezes, quanto ela tá com um problema (E01).

Para o entrevistado 03, que possui lesão total de plexo braquial, nem sempre a sua deficiência torna-se aparente, portanto, para ele, é melhor indicar quando necessita ajuda do que ser auxiliado constantemente. Em contrapartida, o Entrevistado 03 destaca que:

Pois então, alí, na questão de auxílio quando vou realizar alguma compra, é um ponto um pouco complicado, porque os atendentes, dá pra perceber que a grande maioria tenta, se esforça, pra agradar o cliente, só que tem alguns que realmente não sabem como, e também tem aquele medo de chegar e perguntar: 'o que realmente tu precisa de ajuda?' [...] eles deduzem uma coisa e vem, sabe. Já passei por atendimentos de que a dona da loja já me achou muito fofa, e queria me pegar no colo, literalmente, não teve profissionalismo. Já tive pessoas que até a roupa que tava alí em baixo, vinha, me trazia, tipo assim, como se eu fosse uma, não sei, sabe, tem uns que te levam lá, 
parece que é uma "estrela", lá na loja. Ou uma criança, sabe?! Uma bonequinha de porcelana.

Neste sentido, é possível reafirmar que a atenção a pessoa está muito ligada ao que ela aparenta, e que os profissionais não estão preparados para lidar com as diferenças. Isso está inteiramente ligado a forma atitudinal, mas também relaciona-se aos espaços físicos e a disponibilidade de produtos, visto que na maioria das vezes, o que é potente também pode ser um entrave, dependendo da percepção do usuário. Esta percepção emerge ao debater sobre as questões relacionadas ao vestuário. Somente a entrevistada 02 relata não encontrar empecilhos; os entrevistados 03,04 e 05 relatam encontrar poucas dificuldades; já a entrevistada 01 relata encontrar maiores dificuldades, conforme identifica-se na sua fala:

Não tem muita opção, calçados por exemplo, eu uso número 33, isso é número de criança e daí eu quase não encontro calçados, ou se eu encontro, é um 34, que daí fica grande, aí tem que adaptar ele mesmo. No vestuário, a parte de cima, blusa, cropped, enfim, eu consigo comprar tudo em tamanho $\mathrm{P}$, isso ainda consigo quebrar o galho, mas calças, saia, bermuda, short, qualquer outra coisa [...] eu tenho muita sorte de que minha mãe sabe costurar, então eu compro um tamanho, mais ou menos que me serve e depois eu peço para ela cortar, é o único jeito, se eu não tivesse ela, eu não teria como, talvez me vestir, sempre teria que levar em uma costureira (E01).

Diante disto, é possível perceber o quanto os setores responsáveis pela confecção de peças de vestuário não estão preparados para se adaptar às diferenças, não enxergando todos os públicos como segmento de mercado. Considerando os espaços físicos e acessibilidade, os relatos dos entrevistados convergem, estando diretamente relacionados à falta de adaptação, de manutenção dos serviços disponibilizados e desrespeito da população. Pode-se identificar este aspecto na percepção do entrevistado 03:

Acho que as prefeituras, não sei [...] tinha que ter alguém que fizesse fiscalização e fosse atrás pra ver, piso podotátil, por exemplo, no centro que nem, [MUNICÍPIO] tá tudo quebrado, tem pisos quebrados pra tudo que é lado, a condição da calçada, muito precária, tá tudo errado, tudo quebrado, ao meu ver. Vagas de estacionamento também, o pessoal não respeita, né?! (E03).

A entrevistada 04 complementa a reflexão ao afirmar que :

Moro no centro da cidade [...], porém, não consigo ir em uma loja há quatro quadras de casa sozinha, porque minha cadeira motorizada não sobe nas rampas inclinadíssimas e fico lá, patinando. Vagas de estacionamento, eu acho que a cidade se adaptou em relação a 
quantidade, só acho que deveria existir aquelas que a gente possa usar mais tempo, porque elas são de duas horas, deveria existir uma a mais, acredito eu, permanente. Porque tem gente que trabalha ali perto, que possui deficiência e que dificulta, mas existe muita falta de respeito, é o que mais choca, assim e o que mais atrapalha. Eu sou uma pessoa que passo por isso praticamente toda semana, onde eu tenha que chegar e dizer: "Moço, olha, eu tô esperando a topic aqui estacionar, o senhor não pode estacionar aqui", é difícil passar uma semana que eu não faça uma observação assim (E04).

Ao longo das entrevistas, percebe-se o quanto cada pessoa se destaca na busca por seus direitos e também vai se empoderando dos mesmos para exercer sua cidadania, para estar incluído em sociedade, como percebe-se na fala da entrevistada 04, que destaca:

Olha, eu vou te dizer que eu sou insistente com esse tipo de coisa, então assim, eu já fui em estabelecimento comercial, onde tinha vinte e tantos degraus para subir, era lá que eu queria ir, era lá que ia ser comemorado o aniversário de um amigo meu, o estabelecimento comercial teve que dar um jeito de me "botar pra dentro", lá pra cima, porque eu insisto, sabe. Eu acho que é por aí, sabe. Não é deixando eles acomodados do jeito que estão, então, pode ser só eu que insisto, mas eu insisto, né?! (E04).

De maneira geral, todas essas dificuldades impactam diretamente na autonomia dos indivíduos, impedindo-os de exercerem sua cidadania e participarem de forma ativa e igualitária aos demais na sociedade. Ao longo das entrevistas, foi possível perceber que os indivíduos de mais idade costumavam citar inúmeras vezes a quantidade de auxílio que recebiam para realização das suas tarefas. A entrevistada número 02 , na maioria das suas falas, relatou $\mathrm{O}$ quanto seus filhos realizavam as suas tarefas, sendo possível perceber o quanto "o outro fazer" impacta na ausência de autonomia destas pessoas, e mais ainda, o quanto elas nem a percebem, conforme é possível verificar na sua fala:

Por exemplo nos restaurantes, é uma briga, porque a comida cai no chão. Aí tenho que me concentrar um pouquinho mais e sempre levar outra pessoa. No mercado é tranquilo também, mas sempre acompanhada. Sempre faço meu rancho e tudo, sempre acompanhada.", relata. Quando questionada sobre as dificuldades, afirma: "A dificuldade é a questão de altura, se as coisas estão muito altas fica difícil, né?!. Questão de servir nos restaurantes é complicado, porque a mão direita não funciona, mas sempre eu tenho alguém pra me ajudar, um filho, ou alguém (E02).

Para adaptar os ambientes comerciais, locais de lazer, atendimento prestado e disponibilidade de produtos, é necessário entender as limitações de 
cada indivíduo. O que é pensado como ideal nem sempre irá atender a todas as pessoas. Deste modo, todo este trabalho constitui-se como um processo, tendo como seu foco principal a qualidade de vida e autonomia de todas as pessoas, possuam elas alguma limitação ou não. Neste ensejo, conhecer o que as $\mathrm{PcD}$ pensam e o que elas têm a sugerir, é de extrema importância para o contínuo aperfeiçoamento e construção de um ambiente inclusivo.

\section{DISCUSSÃO}

O mundo é pensado em um padrão de normalidade, onde não existe normalidade. As inúmeras manifestações de deficiências, que podem ser descritas por restrições mais leves ou mais graves, exigem do Estado instrumentos legais que garantam direitos de igualdade aos demais, às $\mathrm{PcD}$ (SANTOS, 2008).

O processo de inclusão não pode ser desenvolvido sem que existam legislações, que devem ser pautadas nas necessidades das pessoas, e que sejam previstas constantes fiscalizações efetivas. As leis estão aí, quais sejam: a Lei Brasileira de Inclusão da Pessoa com Deficiência ( $\left.n^{\circ} 13.146 / 15\right)$, que tem como objetivo buscar garantias no que diz respeito às condições de igualdade, direitos e liberdades fundamentais de pessoas com deficiência e a NBR 9050, da Associação Brasileira de Normas Técnicas (ABNT), com título Acessibilidade a edificações, mobiliário, espaços e equipamentos urbanos, que traz as devidas medidas, por meio de parâmetros técnicos que devem ser utilizados em projetos e construções, além de adaptações de edificações, mobiliário e espaços no que se refere à acessibilidade (BRASIL, 2015; ABNT, 2017).

Postas as leis, pode-se perceber, porém, a necessidade de fiscalização do cumprimento das mesmas, o que ainda não é realizado de forma efetiva. $\mathrm{O}$ termo acessibilidade não consta em nenhum dos principais meios de fiscalização de obras públicas, como, por exemplo, no manual FISCOBRAS 2008 do Tribunal de Contas da União, ou na Cartilha 'Obras Públicas: recomendações básicas para a contratação de fiscalização de obras públicas' e nem no manual de auditoria de obras, um indicativo que ainda é incipiente a intervenção do controle externo, mesmo que seja este um assunto que deveria ser incluído na agenda permanente dos órgãos fiscalizadores (LIMA, 2009).

Os indivíduos entrevistados, de uma forma geral, relatam que há necessidade de maior organização dos espaços físicos para pessoas diferentes, além da realização de manutenção das adaptações realizadas. A calçada, por exemplo, é uma via destinada ao trânsito de pedestres, que deve estar em boas condições de segurança, para que todas as pessoas possam trafegar livremente, não havendo obstáculos. Devem atender os rebaixamentos ou rampas para a rua, ter largura mínima de 1,20m, estar com piso firme, regular e em bom estado de conservação, além de serem construídas com materiais duráveis e antiderrapantes. Os elevadores acessíveis devem possuir a dimensão mínima 
1,40m x 1,10m, ter entrada mínima livre de 0,80m, possuir comandos sonoros e em braile, ter corrimão, sinalização, entre outros (SEBRAE, 2014; ABNT, 2017).

Para que os estabelecimentos estejam adaptados para receber todos os tipos de clientes, se faz necessária uma organização diferenciada, que além de adaptações de equipamentos e instalações de sinalizadores, exige qualificação profissional e elaboração de produtos e serviços acessíveis a todos (SEBRAE, 2014).

Na ideia de pensar em produtos e serviços, é importante entender esse segmento como um novo nicho de mercado, visto que a população com deficiência equivale a um grande número de consumidores. Considerando que cerca de $10 \%$ da população mundial possui algum tipo de deficiência, pode-se assim encará-la como um forte segmento de mercado. Além dessa porcentagem, é importante salientar que muitas dessas pessoas possuem outras que as auxiliam para realização de compras e de atividades de vida diárias, tais como utilização de todos os espaços, incluindo os de lazer, sendo assim, o número de pessoas com opções reduzidas pode ser ainda maior (PANOSSO; PANO, 2010).

$\mathrm{Na}$ maioria das falas, é perceptível o quanto os entrevistados não relatam as suas possibilidades de lazer, e sabe-se que historicamente os serviços disponibilizados às pessoas com deficiência são questionados, pois tendem a não considerar tanto as barreiras sociais, mas também o contexto em que essas pessoas estão inseridas. Situações estas que dificultam a participação ativa destas pessoas em sociedade, induzindo a uma cultura de normalidade. Porém, acredita-se que, ainda nos dias de hoje, a deficiência está na sociedade e não no indivíduo (SIMONELLI; CAMAROTO, 2011).

Quanto mais as PCD entendem sua importância na sociedade, maior vai se tornando o seu empoderamento, visto que elas vão entendendo seus direitos e querem que os mesmos sejam cumpridos, por meio de uma inclusão de verdade.

\section{CONCLUSÃO}

Cada sujeito é um sujeito. A inclusão é um processo individual, é olhar para cada sujeito, respeitando as suas necessidades. Porém, diante das falas, é possível perceber o quanto as pessoas vão se resignando com as barreiras encontradas no cotidiano, partindo de uma ideia de que elas não se enquadram naquele convívio, naquele espaço ou naquele ambiente e tomam isso como normal.

É preciso instrumentalizar as pessoas, para que elas possam cobrar os seus direitos, terem insistência sobre acessibilidade comercial e entenderem que elas têm direito a ter voz, ao direito a ter convívio social, lazer e que, ao chegar em um ambiente comercial, elas não tenham que ser reduzidas à deficiência delas, e sim, vistas como potenciais clientes que são, como pessoas que têm seus direitos, vontades e anseios. 
A inclusão da PcD nos ambientes comerciais e locais de lazer vai além da adaptação ergonômica dos espaços. É preciso favorecer as potencialidades e diminuir suas limitações, para que elas se sintam capazes e estimuladas a realizar suas atividades de forma independente, pensando na promoção de igualdade de oportunidades, de fato.

\section{REFERÊNCIAS}

BARDIN, Lawrence. Análise de conteúdo. São Paulo: Edições 70, 2012.

BRASIL. Lei n. 13.146, de 24 de julho de 1991. Institui a Lei Brasileira de Inclusão da Pessoa com Deficiência (Estatuto da Pessoa com Deficiência). Diário Oficial da República Federativa do Brasil, Poder executivo, Brasília, DF, 24 jul. 1991.

CONSOLO, Ana C. P.; GIANULLO, Wilson. Direito dos portadores de deficiência física. VII Jornada de Iniciação Científica da Universidade Presbiteriana Mackenzie de São Paulo. São Paulo, 2011.

LIMA, Luiz H. Acessibilidade para pessoas portadoras de deficiências: requisito da legalidade, legitimidade e economicidade das edificações públicas. Revista do Tribunal de Contas da União (TCU), Rio de Janeiro, v. 116, 2009.

LIMA, Sâmara S. C.; CARVALHO-FREITAS, Maria N. de.; SANTOS, Larissa M. M. Repercussões Psicossociais da Acessibilidade Urbana para as Pessoas com Deficiência Física. Revista Psico, Porto Alegre, v. 44, n. 3, p. 362-371, 2013.

MAZZOTTA, Marcos J. da S.; D'ANTINO, Maria E. F. Inclusão Social de Pessoas com Deficiências e Necessidades Especiais: Cultura, Educação e Lazer. Saúde e Sociedade, São Paulo, v. 20, n. 2, p. 377-389, 2011.

PANOSSO, Alexandre; PANNO, Giovanna. Turismo e acessibilidade na cidade de São Paulo: da teoria à prática. Revista Itinerarium, Rio de Janeiro, v. 3, 2010.

RIO DE JANEIRO. Secretaria Municipal de Saúde do Rio de Janeiro (SMS-RJ). Características gerais da população, religião e pessoas com deficiência. Rio de Janeiro: SMS-RJ, 2010.

SANTOS, Wederson R. dos. Pessoas com Deficiência: nossa maior minoria. Physis Revista de Saúde Coletiva, Rio de Janeiro, v. 18, n. 3, p. 501-519, 2008.

SIMONELLI, Angela P.; CAMAROTTO, João A. Analise de atividades para a inclusão de pessoas com deficiência no trabalho: uma proposta modelo. Revista Gestão de Produção, São Carlos, v. 18, n. 1, p. 13-26, 2011. Disponível em: SEBRAE. Empreendimentos Acessíveis. Comercio: Dicas SEBRAE Empreendimentos Acessíveis. Disponível em: < http://www.sebrae.com.br/Sebrae/Portal\%20Sebrae/Anexos/pecartilha-acessibilidade-com\%C3\%A9rcio.pdf>. Acesso em: 10 mai. 2018. 